\title{
STUDY ON INDIRECT TENSILE STRENGTH OF PLASTIC WASTE BITUMINOUS CONCRETE FOR ROAD CONSTRUCTION
}

\begin{abstract}
Anurag V. Tiwari, Assistant Professor, Department of Civil Engineering, Sipna College of Engineering and Technology, Amravati (M.S), India, email: anuragearth@gmail.com;

Dr. Y R M Rao, Principal, Dr. Pauls Engineering College, Villupuram Dist (T.N), India, email: dryrmrao@rediffmail.com.
\end{abstract}

\section{Abstract}

The rutting and cracking of pavements has become very common problem in India. Also the quantity of plastic waste has significantly increased in the recent year due to industrialization and population growth. Improper disposal of these plastic wastes has caused various environmental problems, hence the alternative use of waste plastic in bituminous concrete for road construction has been encouraged by the community. In the present study the Indirect Tensile Strength Test has been carried out on Marshall Samples confirming to ASTM D6931-12. Three different processes (dry process, wet process and combined process) of mixing of waste plastic were used during experimentation. It was found that the indirect tensile strength (ITS) and tensile strength ratio (TSR) of sample significantly increase up to $8 \%, 6 \%$ and $12 \%$ for dry process, wet process and combined process respectively for LDPE and HDPE type of waste plastic.

Keywords: Plastic Waste, Waste reuse, Road construction, Asphalt concrete, Indirect tensile strength test

\section{INTRODUCTION}

Roadways are considered one of the most important elements of infrastructure and they play an essential role in our daily lives. Pavement is the most important component of the highway section. In India, bituminous pavement is commonly used for highways. Due to increasing traffic intensity, distress such as rutting and cracking of pavements are very common in Indian roads. In the recent years rapid industrialization and large scale infrastructural development in India, has resulted in huge scarcity of construction materials and tremendous increase in the generation of waste products. Disposal of the waste products is a big challenge for the environmental engineers. Plastic waste is the most unwanted land waste all over the world. Some of these materials are non- 
biodegradable and often lead to a waste disposal crisis and environmental pollution. Today availability of plastic waste is enormous throughout the world. The use of plastic materials such as carry bags, cups, etc is constantly increasing. Once used, plastic materials are thrown outside and they remain as waste for years together due to their non-biodegradable nature. This plastic waste gets mixed with water causing the death of fish and other aquatic life who mistake them for food material. Sometimes they are either land filled or incinerated resulting in disposal in an un-eco friendly way polluting the land, air and water. Under these circumstances, an alternative use of these plastic wastes in road construction is a real time solution. Scientists and engineers are constantly searching for different methods to improve the performance of asphalt pavements. Considerable research has been carried out to determine the suitability of a plastic waste modifier in construction of bituminous mixes.

Also, Plastic products have become an integral part in our daily life as a basic need. Plastic waste disposal has become serious problem in India and most developing countries. Plastics are non-biodegradable, synthetic polymers derived primarily from petro-fossil feedstock and made-up of long chain hydrocarbons with additives and can be molded into finished products. Plastics are produced on a massive scale worldwide and their production crosses the 150 million tons per year globally. In India approximately 12 Million tons plastic products are consumed every year which is expected to rise up to 15 million tones by 2015. Its broad range of applications is in packaging films, wrapping materials, shopping and garbage bags, fluid containers, clothing, toys, household and industrial products, and building materials. It is a fact that plastics will never degrade and remains on landscape for several years.

The Indirect Tensile Strength Test is used to determine the tensile properties of the bituminous mixture which can further be related to the cracking properties of the pavement. Low temperature cracking, fatigue and rutting are the three major problems. A higher tensile strength corresponds to a stronger cracking resistance. The Indirect Tensile Strength Test is often used to evaluate the moisture susceptibility of a bituminous mixture. The results of Indirect Tensile Strength Test may be used to evaluate the relative quality of bituminous mixture also for estimating the resistance to cracking. Generally an Indian road undergoes higher moisture damage due to the reason of heavy monsoon. So ITS plays an important role towards better performance of flexible pavement. 


\section{LITERATURE REVIEW}

Israa Saeed Jawad Al-Haydari et al., (2017) reported the possible use of Expanded Polystyrene (EPS) packaging material to improve pavement mixture properties. Expanded polystyrene is one of the waste plastic material which generally used as packaging material and for construction purpose. So, by using EPS as pavement construction material tends to keep the environment clean which also act as bitumen modifier. For 1\%, 2\%, 3\%, 4\% and 5\% of EPS by the weight of bitumen, mechanical and physical properties of bitumen pavement mixture is to be evaluated. Here the indirect tensile test is carried out according to the ASTM D6931-12. The results of this test indicate that increasing the EPS ratio result in a rise in the tensile strength for both conditioned and unconditioned samples. Thus the results are such that EPS does not modify bitumen binder but increases the mechanical performance of pavement.

Hamed M. Jassim et al., (2014) used the plastic waste to enhance Marshall properties and moisture resistance of hot mix bitumen. The increasing amount of plastic was derived from different types and different sizes of bottles which generally used to contain liquid product. Thus disposal becomes a major problem due to their non-biodegradability. So, the aim of this research is to determine the properties of plastic waste particles which will provide the ultimate performance of hot mix bitumen. In this study plastic waste was added at $5 \%, 10 \%, 15 \%, 20 \%$ and $25 \%$ by weight of Bitumen. Thus the results reveal that plastic waste with fine particle size, thin thickness and $15 \%$ by weight of bitumen results in enhancing the Marshall Stability and resistance to water damage. Thus the recommended proportion of the added plastic waste is up to $15 \%$ by the weight of bitumen that can be used for construction of road pavement to improve the marshal stability and moisture resistance.

Sabina et al., (2009) evaluated the performance of bituminous concrete mix containing Plastic/Polymer (PP) which significantly increases compared to the conventional bituminous concrete mix. Resistance to deformation of bitumen concrete modified with low density polythene at 5\% improved the properties compared to the conventional one. Indirect Tensile Strength test was conducted at $25^{\circ} \mathrm{C}$ to measure splitting tensile strength of bituminous mixes by application of diametric compressive force on a cylindrical specimen placed with its horizontal axis between plates of compression testing machine. The bituminous concrete mixes containing Plastic/Polymer ( $8 \%$ and $15 \%$ by weight of bitumen) prepared with 60/70 penetration grade bitumen shows improvement in properties like Marshall stability, Indirect tensile strength and retained stability. 
Dipankar Sarkar et al., (2016) studied the innovativeuse of brick aggregate along with plastic modified bitumen in preparation of bituminous concrete for road. To prepare the bituminous mix with such an aggregate $1 \%, 3 \%, 6 \%, 8 \%$ and $10 \%$ waste plastic by the weight of bituminous added to hot bitumen, for this Marshall method for mix design was used. Indirect Tensile Strength, Tensile strength ratio and stability were determined. The mix with $8 \%$ plastic shows higher stability (increase by 32\%) and Higher Tensile Strength (increase by $65 \%$ ). It is observed that the stripping value is least for mix $8 \%$ and $10 \%$ plastic modified bitumen.

A.U. Ravishankar et al., (2013) proposed the use of processed plastics for the modification of bituminous concrete mix in order to cater the need of varying climatic conditions and heavy axle loads on the pavements as well as to minimize plastic waste. Bitumen added to the mix to prepared bituminous concrete and waste plastics added to the mix in different percentage by weight of bitumen. The waste plastic was directly added to the mix. Marshall Method of mix design was adopted to find out the optimum bitumen content. Marshall specimen were prepared for bitumen content of 4.5, 5.0, 5.5 and 6.0 percent by weight of mix. The waste plastic was added at 3\%,6\%, 10\%, and $14 \%$ by weight of bitumen. It was observed that the Marshall Stability value increases with increase in percentage of waste plastics up to 6 percent and then decreases. For unconditioned and conditioned samples, the Indirect Tensile Strength values increased by 29 percent and 38 percent respectively for the mix with 6 percent plastic wastes.

Ashok Pareek et.al. (2012) carried out the study for the property of polymer modified bitumen mix is significantly higher than the conventional mix. The indirect tensile strength test is carried out on Marshall Specimen prepared at the optimum bitumen content at $30^{\circ} \mathrm{C}$. The indirect tensile strength of conventional and polymer modified bitumen mixes were found to be $493 \mathrm{kpa}$ and $591 \mathrm{kpa}$ respectively. It shows that indirect tensile strength of the modified mix is $20 \%$ higher than the conventional mix. It also states that when Polymer modified bitumen was used the value of Marshall Stability is increased by $27 \%$. It has been shown that the rutting resistance, cracking resistance, indirect tensile strength improved significantly of the bitumen concrete mix with the addition of polymer modified bitumen.

V.S.Punith et.al. (2011) studied that by adding 5\% PE content to bitumen concrete gives better Indirect Tensile Strength characteristics. Conditioning was done by keeping the specimen in water maintained at $60^{\circ} \mathrm{C}$ for 24 hour. The result gives the Tensile strength ratio value more than that of conventional mixture up to $95.9 \%$ for modified mixture, which indicates that PE- modified 
mixtures are less susceptible to moisture damage. Which means it does not deteriorate easily by atmospheric condition. Hence, from the results PEmodified mixture found to be less susceptible to moisture induced damaged compared to conventional mixtures as indicated by higher retained stability and higher tensile strength ratio.

A.V. Tiwari et. al (2017) stated that waste plastic is accumulated all over the world causing serious environmental problems. They study the addition of plastic waste in bituminous concrete using dry process of mixing for road construction. The study evaluates the addition of shredded waste plastic in the bituminous concrete which results in a significant increase in the stability value and Marshall Properties of the mix. The study reveals that the use of waste plastic in bituminous concrete is safe and sustainable for road construction. The experiment was conducted into two phases. The first phase consists of calculating the optimum value of the bitumen and second phase consists of optimizing the quantity of plastic waste used to replace the bitumen. Dry process was used to prepare Marshall Samples. In this process the coarse aggregates and fine aggregate and fly ash were heated to $170^{\circ} \mathrm{C}$. The shredded plastic waste retaining on $2.36 \mathrm{~mm}$ sieve is added in proportion by weight to the hot aggregate. The waste plastic LDPE, PVC and HDPE was added varying from $0 \%, 2 \%, 4 \%, 6 \%, 8 \%, 10 \%$ and $12 \%$ by the weight of bitumen. This plastic gets coated over the aggregate uniformly. Immediately, the hot Bitumen at a temperature of $160^{\circ} \mathrm{C}$ is added to the mixture. After proper mixing, the mix was placed in the compaction mould and compacted with 75 blows on both sides to get Marshall Samples. The stability and flow were obtained by testing the sample on the digital Marshall frame and the average values for Bulk specific Gravity, AV, VMA and VFB were calculated and graphs were plotted. The values obtained stability values are corrected after applying the correction for thickness of the sample. From the study it can be concluded that addition of plastic improves the Marshall properties of the mix. The Addition of $8 \%$ of the LDPE and HDPE plastic waste improves the stability value of the bituminous mix which results is the increase in the toughness of the mix. The roads can withstand heavy traffic and shows better service life.

According to A.V Tiwari et. al (2017) the major portion of highway in India is flexible. Recent research suggests that these plastic materials can be used in road construction as a binding material. Polyethylene is an extensively used plastic material, and it has been found to be one of the most effective polymer additives in road construction. From the investigation on utility of plastic waste as an additive for bituminous concrete using wet process of mixing it can be concluded that addition of plastic improves the Marshall properties of 
ROMANIAN JOURNAL

OF TRANSPORT INFRASTRUCTURE

Anurag V. Tiwari, Dr. Y R M Rao

Study on indirect tensile strength of plastic waste bituminous concrete for road construction

the mix. The Addition of $6 \%$ of the LDPE and HDPE plastic waste improves the stability value of the bituminous mix which results is the increase in the toughness of the mix. The roads can withstand heavy traffic and show better service life. Due to the addition of plastic waste, the flow value increases, resulting in the improvement of the workability. Addition of plastic waste results in decrease in the air voids which reduces the bleeding of bitumen. The volumetric and Marshall properties of the mix show the acceptable trends and could satisfy the specified limits.

\section{Materials and Methods}

Various materials used in the present study are bitumen, aggregate (fine and coarse), filler, and shredded plastic waste. The bitumen used for present study is of 60/70 penetration grade and is obtained from BPCL, Nagpur and PWD, Amravati. Coarse aggregates, fine aggregates and fly ash were collected from local producer of crushed aggregates. The plastic waste was segregated from the municipal waste and shredded at the local plastic waste recycling plant at MIDC, Amravati. Table no. 1 and Table no. 2 show the physical properties of the aggregates and bitumen respectively.

Table 1. Physical Properties of Coarse Aggregates

\begin{tabular}{|c|c|c|c|c|c|}
\hline Sr.no & Parameter & $\begin{array}{l}\text { No. of tests } \\
\text { Performed }\end{array}$ & Test Result & $\begin{array}{l}\text { Specification } \\
\text { Requirement }\end{array}$ & Standard \\
\hline 1 & Impact value & 3 & $22.40 \%$ & $\operatorname{Max} 30 \%$ & $\begin{array}{c}\text { IS : } 2386 \text { (Part } \\
\text { IV) - } 1963\end{array}$ \\
\hline 2 & Abrasion value & 3 & $28.10 \%$ & $\operatorname{Max} 40 \%$ & $\begin{array}{c}\text { IS : } 2386 \text { (Part } \\
\text { IV) - } 1963\end{array}$ \\
\hline 3 & Crushing value & 3 & $24.30 \%$ & $\operatorname{Max} 30 \%$ & $\begin{array}{c}\text { IS : } 2386 \text { (Part } \\
\text { IV) - } 1963\end{array}$ \\
\hline 4 & $\begin{array}{l}\text { Combined } \\
\text { Elongation } \\
\text { index and } \\
\text { Flakiness index }\end{array}$ & 3 & $17.20 \%$ & $\operatorname{Max} 30 \%$ & $\begin{array}{c}\text { IS : } 2386 \text { (Part I) } \\
-1963\end{array}$ \\
\hline 5 & Specific gravity & 6 & $\begin{array}{c}20 \mathrm{~mm}: 2.830 \\
\mathrm{~kg} / \mathrm{m}^{3} \\
10 \mathrm{~mm}: 2.792 \\
\mathrm{~kg} / \mathrm{m}^{3}\end{array}$ & - & $\begin{array}{c}\text { IS : } 2386 \text { (Part } \\
\text { IV) - } 1963\end{array}$ \\
\hline 6 & $\begin{array}{l}\text { Water } \\
\text { Absorption }\end{array}$ & 3 & $0.1 \%$ & $\operatorname{Max} 2 \%$ & $\begin{array}{c}\text { IS: } 2386 \text { (Part } \\
\text { III)-1963 }\end{array}$ \\
\hline
\end{tabular}


ROMANIAN JOURNAL

OF TRANSPORT INFRASTRUCTURE

Anurag V. Tiwari, Dr. Y R M Rao

Study on indirect tensile strength of plastic waste bituminous concrete for road construction

Table 2. Physical Properties of Bitumen

\begin{tabular}{|c|l|c|c|c|}
\hline Sr.no & Parameter & Test Result & Specification Requirement & Standard \\
\hline 1 & Penetration & 68 & $65-90$ & IS : 1203-1978 \\
\hline 2 & Softening point & $53^{\circ} \mathrm{C}$ & $40-60{ }^{\circ} \mathrm{C}$ & IS : 1205-1978 \\
\hline 3 & Specific Gravity & $1.01 \mathrm{~kg} / \mathrm{m}^{3}$ & Min $0.99 \mathrm{~kg} / \mathrm{m}^{3}$ & IS : 1202:1978 \\
\hline 4 & Ductility & $87 \mathrm{~mm}$ & Min $75 \mathrm{~mm}$ & IS $: 1208-1978$ \\
\hline
\end{tabular}

The sieve analysis test was used to determine the aggregate sizes. Through this sieve test, the proportion of coarse aggregates, fines aggregate and filler was determined and ensuring the aggregate were well blended within the gradation limit as specified in MORTH shown in Table no. 3.

Table 3. Gradation of Aggregates

\begin{tabular}{|c|c|c|c|c|c|c|c|}
\hline \multirow{2}{*}{$\begin{array}{c}\text { Sieve Size } \\
(\mathrm{mm})\end{array}$} & \multicolumn{4}{|c|}{ Percentage Passing of Aggregates } & \multicolumn{2}{c|}{$\begin{array}{c}\text { MORTH Specification } \\
\text { limit }\end{array}$} \\
\cline { 2 - 9 } & $20 \mathrm{~mm}$ & $10 \mathrm{~mm}$ & $\begin{array}{c}\text { Stone } \\
\text { Dust }\end{array}$ & Filler & Combined & Maximum & Minimum \\
\hline 37.5 & 100 & 100 & 100 & 100 & 100 & & 100 \\
\hline 26.5 & 100 & 100 & 100 & 100 & 100 & 100 & 90 \\
\hline 19 & 62 & 100 & 100 & 100 & 89 & 95 & 71 \\
\hline 13.2 & 18 & 96 & 100 & 100 & 74 & 80 & 56 \\
\hline 4.75 & 0 & 54 & 92 & 100 & 52 & 54 & 38 \\
\hline 2.36 & 0 & 14 & 76 & 100 & 33 & 42 & 28 \\
\hline 0.3 & 0 & 5 & 23 & 100 & 14 & 21 & 7 \\
\hline 0.075 & 0 & 2 & 7 & 92 & 7 & 8 & 2 \\
\hline $\begin{array}{l}\text { Proportion } \\
\text { Percentage }\end{array}$ & 30 & 35 & 30 & 5 & 100 & & \\
\hline
\end{tabular}



Figure 1. Aggregate Gradation 
The experiment was conducted using three different processes of mixing waste plastic into bituminous concrete viz. Dry process, wet process and combined process. In Dry process the coarse aggregates and fine aggregate and fly ash were heated to $170^{\circ} \mathrm{C}$. The shredded plastic waste retaining on $2.36 \mathrm{~mm}$ sieve is added in proportion by weight to the hot aggregate. The waste plastic LDPE, PVC and HDPE was added varying from $0 \%, 2 \%, 4 \%, 6 \%, 8 \%, 10 \%$ and $12 \%$ by the weight of bitumen. This plastic gets coated over the aggregate uniformly. Immediately the hot Bitumen at $160^{\circ} \mathrm{C}$ is added to the mixture. Similarly in wet process the coarse aggregates and fine aggregate and fly ash were heated to $170^{\circ} \mathrm{C}$. The shredded plastic waste retaining on $2.36 \mathrm{~mm}$ sieve is added in proportion by weight to the hot bitumen which was immediately added to the mixture at $160^{\circ} \mathrm{C}$. In case of combined process certain percentage of waste plastic LDPE, PVC and HDPE was added varying from 6\%, 8\%, and 10\% using dry process and $4 \%, 6 \%$ and $8 \%$ using wet process to prepare sample of combined process. After proper mixing the mix was placed in the compaction mould and compacted with 75 blows on both sides to get Marshall Samples. Three samples were prepared for each proportion and the average was calculated. During the experiment PVC type of plastic waste was also used but while spreading the shredded PVC plastic on heated aggregate some gases were coming out of the mix and hence PVC plastic was not used for further experiment.

The IDT strength of bituminous mixtures is conducted by loading a Marshall specimen across its vertical diametral plane at a $50 \mathrm{~mm} / \mathrm{min}$ rate of deformation and $25^{\circ} \mathrm{C}$ through two opposite loading strips. This loading configuration develops a relatively uniform tensile stress perpendicular to the direction of the applied load and along the vertical diametrical plane, ultimately causing the specimen tested to fail by splitting along the vertical diameter. A $12.7 \pm 0.3 \mathrm{~mm}$ wide strip loading is used for $101.6 \mathrm{~mm}$ diameter specimen to provide a uniform loading with which produces a nearly uniform stress distribution. The static indirect tensile strength of a specimen is determined using the procedure outlined in ASTM D 6931. Tensile failure occurs in the sample rather than the compressive failure. The compressive load indirectly creates a tensile load in the horizontal direction of the sample.

The peak load is recorded and it is divided by appropriate geometrical factors to obtain the split tensile strength using the following equation:

Where,

$$
\mathrm{St}=\frac{2000 \mathrm{P}}{\pi \mathrm{tD}}
$$

$\mathrm{St}=$ IDT strength, in $\mathrm{kPa}$

$\mathrm{P}=$ Maximum load, in $\mathrm{N}$ 
ROMANIAN JOURNAL

OF TRANSPORT INFRASTRUCTURE

Anurag V. Tiwari, Dr. Y R M Rao

Study on indirect tensile strength of plastic waste bituminous concrete for road construction

$\mathrm{t}=$ specimen height immediately before test, in $\mathrm{mm}$

$\mathrm{D}=$ specimen diameter, in $\mathrm{mm}$

Tensile strength ratio (TSR) is a measure of water sensitivity. It is the ratio of the tensile strength of water conditioned specimen, (ITS wet, $60^{\circ} \mathrm{C}$, and $24 \mathrm{~h}$ ) to the tensile strength of unconditioned specimen (ITS dry, $25^{\circ} \mathrm{C}$ ) which is expressed as a percentage. A higher TSR value typically indicates that the mixture will perform well with a good resistance to moisture damage. The higher the TSR value, the lesser will be the strength reduction by the water soaking condition, or the more water-resistant it will be. Moisture damage in bituminous mixes refers to the loss of serviceability due to the presence of moisture. The extent of moisture damage is called the moisture susceptibility. Tensile Strength Ratio value can be calculated by following equation:

Where,

$$
\mathrm{TSR}=\frac{\text { ITS CONDITIONED }}{\text { ITS UNCONDITIONED }} \times 100
$$

TSR $=$ Tensile Strength Ratio (\%)

ITS Conditioned $=$ the indirect tensile strength of the conditioned specimens $(\mathrm{kPa})$

ITS Unconditioned $=$ the indirect tensile strength of the unconditioned specimens $(\mathrm{kPa})$

\section{RESULTS}

Table 4. Results for ITS and TSR for Dry and Wet process of mixing

\begin{tabular}{|c|c|c|c|c|c|c|c|}
\hline \multirow{3}{*}{$\begin{array}{c}\text { Plastic } \\
\text { waste } \\
\text { content } \\
\% \\
\end{array}$} & \multirow{3}{*}{$\begin{array}{c}\text { Type } \\
\text { of } \\
\text { Plastic } \\
\text { Waste } \\
\end{array}$} & \multicolumn{3}{|c|}{ Dry Process } & \multicolumn{3}{|c|}{ Wet Process } \\
\hline & & \multicolumn{2}{|c|}{ ITS (MPa) } & \multirow{2}{*}{$\begin{array}{c}\text { TSR } \\
(\%)\end{array}$} & \multicolumn{2}{|c|}{ ITS (MPa) } & \multirow{2}{*}{$\begin{array}{c}\text { TSR } \\
(\%)\end{array}$} \\
\hline & & Unconditioned & Conditioned & & Unconditioned & Conditioned & \\
\hline 0 & & 0.7906 & 0.4927 & 62.65 & 0.7906 & 0.4927 & 62.65 \\
\hline 2 & LDPE & 0.9015 & 0.5884 & 65.24 & 0.7233 & 0.4832 & 66.81 \\
\hline 4 & LDPE & 0.9490 & 0.6598 & 69.50 & 0.7821 & 0.5786 & 73.95 \\
\hline 6 & LDPE & 1.0004 & 0.8326 & 83.20 & 0.8928 & 0.7951 & 89.06 \\
\hline 8 & LDPE & 1.0984 & 1.0675 & 97.17 & 0.8851 & 0.7432 & 83.98 \\
\hline 10 & LDPE & 0.9931 & 0.9288 & 93.56 & 0.7903 & 0.6413 & 81.24 \\
\hline 12 & LDPE & 0.9233 & 0.8474 & 91.81 & 0.7455 & 0.5992 & 80.36 \\
\hline 2 & HDPE & 0.8947 & 0.5890 & 65.77 & 0.7537 & 0.5718 & 76.09 \\
\hline 4 & HDPE & 0.9252 & 0.6464 & 69.90 & 0.7330 & 0.5435 & 74.18 \\
\hline 6 & HDPE & 0.9842 & 0.8159 & 82.93 & 0.9239 & 0.8107 & 87.75 \\
\hline 8 & HDPE & 1.0613 & 1.0244 & 96.53 & 0.8782 & 0.7349 & 83.75 \\
\hline 10 & HDPE & 1.0054 & 0.9126 & 90.78 & 0.8130 & 0.6714 & 82.67 \\
\hline 12 & HDPE & 0.9485 & 0.8649 & 91.20 & 0.7513 & 0.5861 & 77.98 \\
\hline
\end{tabular}


ROMANIAN JOURNAL

OF TRANSPORT INFRASTRUCTURE

Anurag V. Tiwari, Dr. Y R M Rao

Study on indirect tensile strength of plastic waste bituminous concrete for road construction

It is observed that the indirect tensile strength of sample significantly increases up to $8 \%, 6 \%$ and $12 \%$ for dry process, wet process and combined process respectively for LDPE and HDPE type of waste plastic.

ITS values for unconditioned sample increased by $38.93 \%, 12.92 \%$ and $51.13 \%$ for the mix of $8 \%, 6 \%$ and $12 \%$ LDPE plastic using dry process, wet process and combined process respectively as compared to the ITS value of conventional mix. ITS values for conditioned sample increased by $116 \%$, $61.37 \%$ and $124 \%$ for the mix of $8 \%, 6 \%$ and 12\% LDPE plastic using dry process, wet process and combined process respectively as compared to the ITS value of conventional mix.

Similarly ITS values for unconditioned sample increased by $34.23 \%$, $16.86 \%$ and $47.43 \%$ for the mix of $8 \%, 6 \%$ and $12 \%$ HDPE plastic using dry process, wet process and combined process respectively as compared to the ITS value of conventional mix. ITS values for conditioned sample increased by $107.91 \%, 64.54 \%$ and $122.38 \%$ for the mix of $8 \%, 6 \%$ and $12 \%$ HDPE plastic using dry process, wet process and combined process respectively as compared to the ITS value of conventional mix.

It is observed that the tensile strength ratio (TSR) of sample significantly increases up to $8 \%, 6 \%$ and $12 \%$ for dry process, wet process and combined process respectively.

Table 5. Results for ITS and TSR for Combined process of mixing

\begin{tabular}{|c|c|c|c|c|c|}
\hline \multirow{3}{*}{$\begin{array}{l}\text { Type of } \\
\text { Plastic } \\
\text { Waste }\end{array}$} & \multicolumn{5}{|c|}{ Combined Process } \\
\hline & \multirow{2}{*}{$\begin{array}{c}\% \text { of plastic } \\
\text { waste added } \\
\text { using Dry } \\
\text { Process }\end{array}$} & \multirow{2}{*}{$\begin{array}{c}\% \text { of plastic } \\
\text { waste added } \\
\text { using Wet } \\
\text { Process }\end{array}$} & \multicolumn{2}{|c|}{ ITS (MPa) } & \multirow{2}{*}{$\begin{array}{l}\text { TSR } \\
(\%)\end{array}$} \\
\hline & & & Unconditioned & Conditioned & \\
\hline & \multicolumn{2}{|c|}{0} & 0.7906 & 0.4927 & 62.65 \\
\hline LDPE & 6 & 4 & 0.8259 & 0.5559 & 67.40 \\
\hline LDPE & 6 & 6 & 0.9415 & 0.7301 & 77.74 \\
\hline LDPE & 8 & 4 & 1.1949 & 1.1063 & 92.53 \\
\hline LDPE & 8 & 6 & 1.0977 & 0.9762 & 88.91 \\
\hline LDPE & 8 & 8 & 1.0211 & 0.9335 & 91.42 \\
\hline LDPE & 10 & 6 & 0.9897 & 0.8742 & 88.30 \\
\hline LDPE & 10 & 8 & 0.9275 & 0.7545 & 81.31 \\
\hline HDPE & 6 & 4 & 0.8258 & 0.5815 & 70.38 \\
\hline HDPE & 6 & 6 & 0.9298 & 0.7191 & 77.40 \\
\hline HDPE & 8 & 4 & 1.1656 & 1.0957 & 94.00 \\
\hline HDPE & 8 & 6 & 1.0599 & 0.9321 & 87.94 \\
\hline
\end{tabular}




\section{ROMANIAN JOURNAL \\ OF TRANSPORT INFRASTRUCTURE}

Anurag V. Tiwari, Dr. Y R M Rao

Study on indirect tensile strength of plastic waste bituminous concrete for road construction

\begin{tabular}{|c|c|c|c|c|c|}
\hline HDPE & 8 & 8 & 1.0685 & 0.9458 & 88.52 \\
\hline HDPE & 10 & 6 & 0.9594 & 0.8533 & 89.03 \\
\hline HDPE & 10 & 8 & 0.8735 & 0.7128 & 81.65 \\
\hline
\end{tabular}

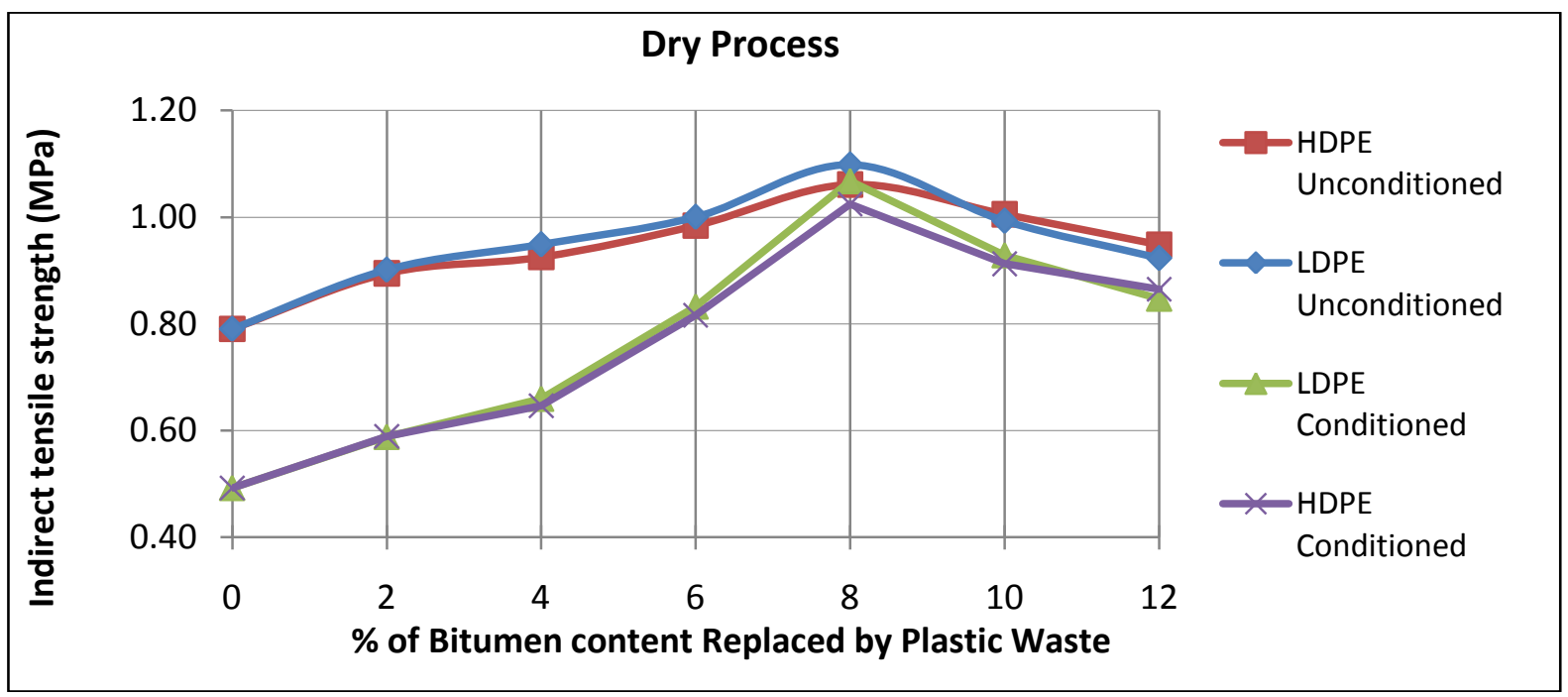

Figure 2. Results for ITS using Dry process of mixing

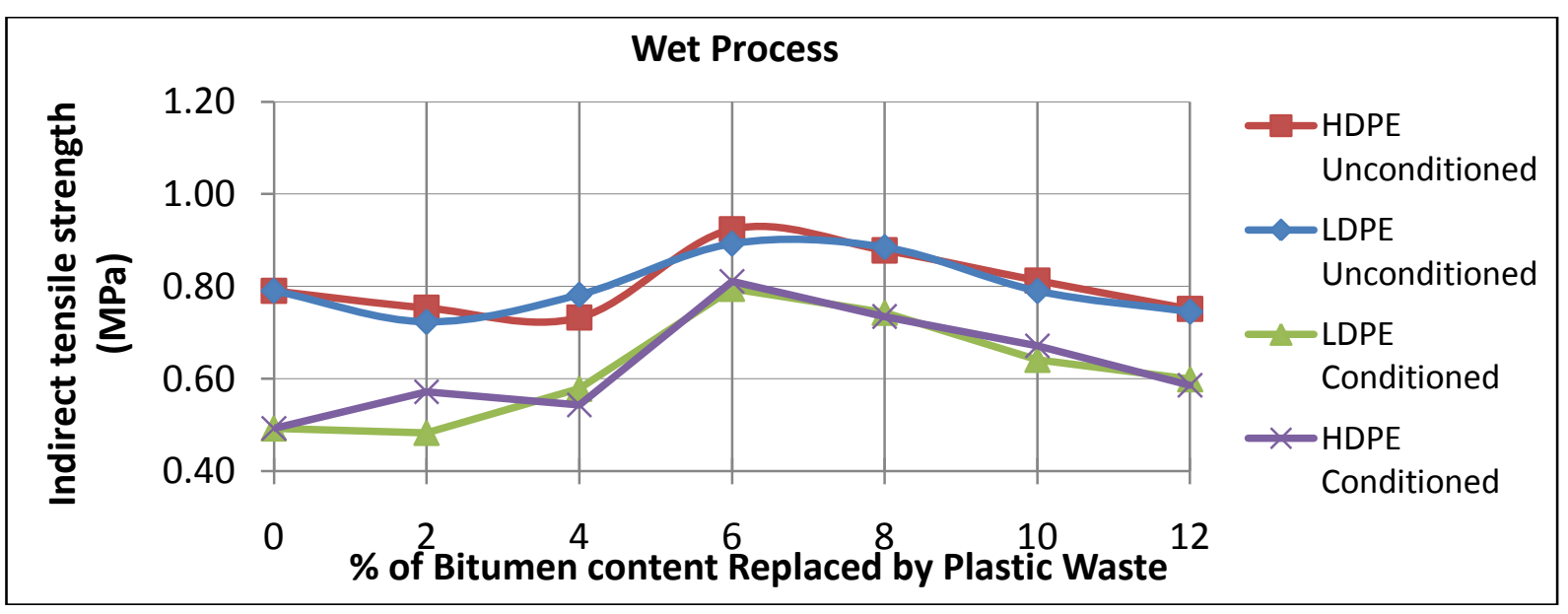

Figure 3. Results for ITS using Wet process of mixing 
ROMANIAN JOURNAL

OF TRANSPORT INFRASTRUCTURE

Anurag V. Tiwari, Dr. Y R M Rao

Study on indirect tensile strength of plastic waste bituminous concrete for road construction

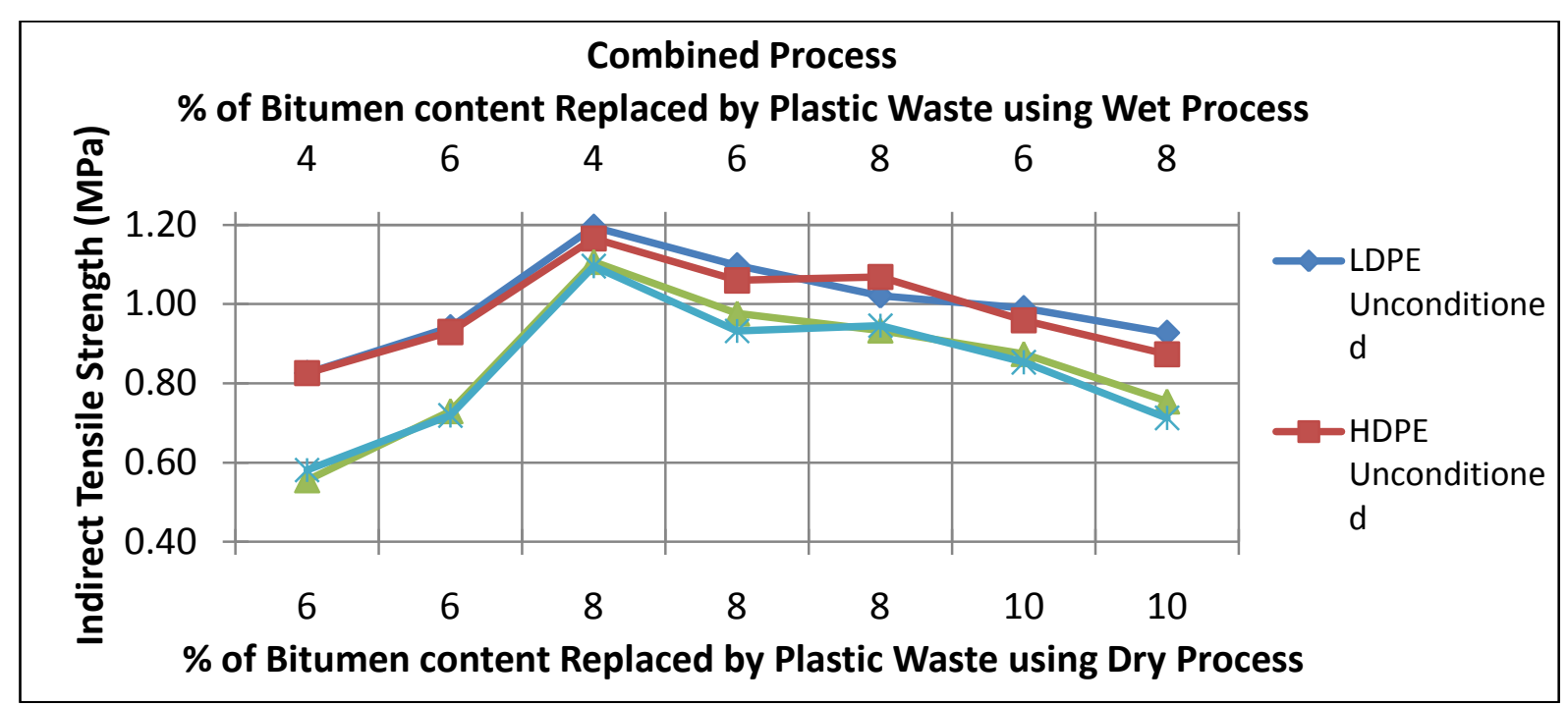

Figure 4. Results for ITS using combined process of mixing

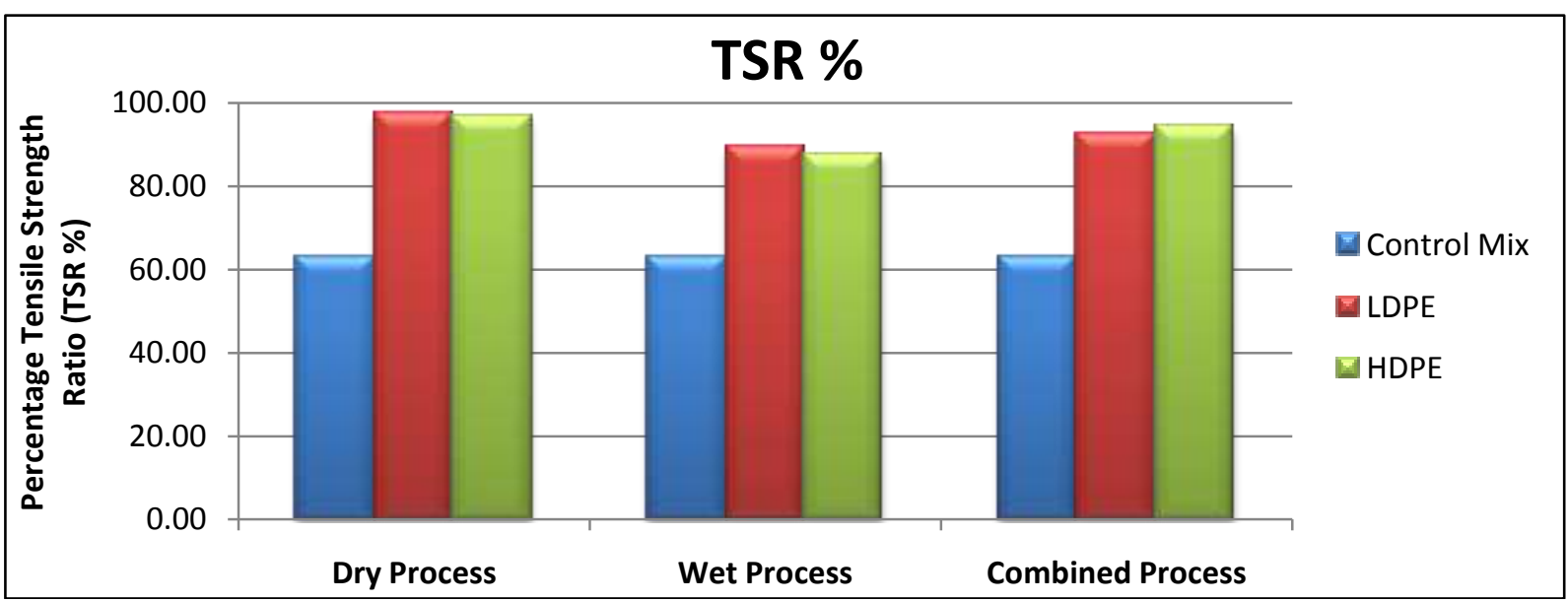

Figure 5. Results for TRS at optimized values of LDPE and HDPE content

\section{CONCLUSION}

On the basis of analysis of results obtained in the present study, the following conclusions are drawn:

- The value of Indirect Tensile Strength at $8 \%, 6 \%$ and $12 \%$ are optimum plastic content is found for dry process, wet process and combined process respectively. More over the Indirect Tensile Strength has significantly increased than that of conventional mix. Hence pavement undergoes less susceptible to moisture induced damage. Thus, it is advantageous to use it. 
- The Tensile Strength Ratio (TSR) value increases for LDPE and HDPE at addition $8 \%, 6 \%$ and $12 \%$ for dry process, wet process and combined process respectively. The higher TSR value the lesser will be the strength reduction by the water soaking condition, or the more water-resistant it will be. It means bituminous mixes refers to the higher serviceability.

- A higher tensile strength corresponds to a stronger cracking resistance. At the same time, mixtures that are unable to tolerate higher strain are more likely to resist cracking. If the tensile strength is higher, then three major distress mechanisms i.e. low temperature cracking, fatigue and rutting can be avoided.

- The waste generated from the thermal plant is very difficult to dispose off. But if we use fly ash as filler, it helps with the disposal of fly ash and improves the property of bituminous mix.

\section{REFERENCES}

[1]. Israa Saeed Jawad Al-Haydari and Ghadah Ghassan Masued (2017), "Benefit of using Expanded Polystyrene Packaging Material to Improve Pavement Mixture Properties", Applied Research Journal, Vol.3 (Issue 11), PP.332-342.

[2]. Dr. Hamed M. Jassim, Omar T. Mahmood and Sheelan A. Ahmed (2014), "Optimum use of Plastic Waste to Enhance the Marshall Properties and Moisture Resistance of Hot Mix Bitumen", International Journal of Engineering Trends and Technology, Vol.7, No.1, P.223.

[3]. Sabina, Tabrez A. Khan, Sangita, D. K. Sharma and B. M. Sharma (2009), "Performance Evaluation of Waste Plastic/Polymer Modified Bituminous Concrete Mixes", Journal of Scientific \& Industrial Research, Vol.68 (11), PP.975-979.

[4]. Dipankar Sarkar and Manish pal (2016),“ A Laboratory Study Innovating use of Brick Aggregate along with Plastic Modified Bitumen in Preparation of Bituminous Concrete for The Road of Tripura", ARPN Journal of Engineering and Applied Science, vol.11, no.1, pp 570-576

[5]. A. U. Ravi Shankar, K. Koushik and Goutham Sarang (2013), "Performance Studies On Bituminous Concrete Mixes Using Waste Plastics", Highway Research Journal, Vol.6, No.1, pp 1-11.

[6]. Pareek A.,Gupta T. and Sharma R.K (2012), "Performance of polymer modified bitumen for flexible pavement", International Journal of Structural and Civil Engineering Research, Vol. 1, No.1. pp 77-86. 


\section{ROMANIAN JOURNAL \\ OF TRANSPORT INFRASTRUCTURE}

Anurag V. Tiwari, Dr. Y R M Rao

Study on indirect tensile strength of plastic waste bituminous concrete for road construction

[7]. Punith. V.S., Veeraragavan. A. and Amirkhnian S.N (2011), "Evaluation of Reclaimed Polyethylene Modified Bitumen Concrete Mixture", International Journal of Pavement Engineering, Vol 4,No. 1,pp.1-10.

[8]. Tiwari, A.V., Rao, Y., R., M., Study of plastic waste bituminous concrete using dry process of mixing for road construction. Transport \& Logistics: the International Journal, 2017; Volume 17, Issue 43, November 2017, ISSN 2406-1069

[9]. Tiwari, Anurag Virendra, and Y. R. M. Rao. "Investigation on Utility of Plastic Waste as an Additive for Bituminous Concrete Using Wet Process of Mixing." Science and Transport Progress. Bulletin of Dnipropetrovsk National University of Railway Transport 6 (72) (2017): 83-92.

[10]. IS 2386 (Part I) - 1963 Indian Standard. Methods of Test For Aggregates for Concrete -Part I Particle Size And Shape.

[11]. IS 2386-3 - 1963 Methods Of Test For Aggregates For Concrete - Part III Specific Gravity, Density, Voids, Absorption and Bulking

[12]. IS 2386 (Part IV) - 1963 Indian Standard. Methods of Test for Aggregates for Concrete. Part IV Mechanical Properties

[13]. IS 1203: 1978 Methods of testing tar and bituminous material - Determination of penetration

[14]. IS 1205: 1978 Methods for testing tar and bituminous materials - Determination of Softening point

[15]. IS 1202: 1978 Methods of testing tar and bituminous materials - Determination of specific gravity

[16]. IS 1208: 1978 Methods of testing tar and bituminous material - Determination of ductility

[17]. ASTM D 6931 (2007), “Indirect Tensile (IDT) Strength for Bituminous Mixtures", American Society for Testing and Materials, Philadelphia. 